\title{
PÓS-TRATAMENTO DE EFLUENTE DE REATOR UASB UTILIZANDO SISTEMAS “WETLANDS” CONSTRUÍDOS
}

\author{
José Tavares de Sousa ${ }^{1}$, Adrianus C. van Haandel², Paulo Rogério da Silva Cosentino ${ }^{3}$ \& \\ Adriana Valéria Arruda Guimarães ${ }^{4}$
}

\begin{abstract}
RESUMO
O presente trabalho avalia o desempenho de sistemas "wetlands" utilizados no pós-tratamento de efluente de um reator anaeróbio de manta de lodo (UASB), com relação à remoção de matéria orgânica e formas de nitrogênio e fósforo. O reator UASB tratava esgotos sanitários brutos provenientes da cidade de Campina Grande, PB, e o efluente produzido era bombeado para os quatro sistemas "wetlands", em escala piloto, sendo três cultivados com macrófitas emergentes (Juncus $s p$ ) e um sem cultivo, para o controle da pesquisa. Todos os sistemas foram operados com diferentes cargas hidráulicas: 4,5; 3,3 e 2,3 $\mathrm{cm} \mathrm{dia}{ }^{-1}$. Os resultados obtidos durante as vinte e seis semanas de operação foram promissores e se observaram eficiências médias de remoção de matéria orgânica (DQO) entre 76 e 84\%, para cargas aplicadas variando de 6,58 a 14,2 $\mathrm{g}$ DQO m $\mathrm{m}^{-2} \mathrm{dia}^{-1}$. Na remoção de nutrientes, verificou-se a produção de efluentes com concentrações médias de $6,1 \mathrm{mg} \mathrm{N}^{-N_{4}} \mathrm{~L}^{-1}$ e com relação ao nitrogênio total: 7,6 NTK mg L-1 com remoção respectivamente de 86 e $87 \%$; já para fósforo total, o sistema "wetlands", operando com carga hidráulica de $2,3 \mathrm{~cm} \mathrm{dia}^{-1}$, produziu efluente sem presença de fósforo ( $100 \%$ de remoção).
\end{abstract}

Palavras-chave: “wetlands" construído, pós-tratamento, remoção de nutrientes, macrófitas

\section{POST TREATMENT OF THE EFFLUENT FROM A UASB REACTOR USING CONSTRUCTED "WETLANDS” SYSTEMS}

\begin{abstract}
In this paper an evaluation is made of the performance of "wetlands" systems used for post treatment of the effluent from a UASB reactor. The removal of organic material, forms of nitrogen and phosphorus were evaluated. The UASB reactor treats municipal sewage in the City of Campina GrandeBrazil. The produced effluent was pumped to four pilot scale "wetlands" units. Three of these were cultivated with emerging macrophytes (Juncus $s p$ ) whereas the fourth was operated without vegetation as a control unit. The three units with vegetation were operated with different hydraulic loads: 4.5, 3.3 and $2.3 \mathrm{~cm} \mathrm{~d}^{-1}$. The results obtained during the operation period of twenty six weeks were promising. The observed removal efficiencies of organic matter (measured as COD) ranged from 76 to $84 \%$ for application load varying from 6.58 to $14.2 \mathrm{~g} \mathrm{COD} \mathrm{m}^{2} \mathrm{~d}^{-1}$. With respect to nutrient removal, it is shown

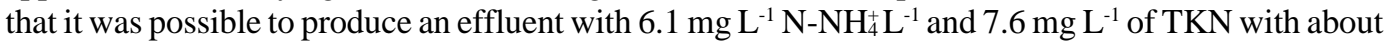
86 and $87 \%$ removal, respectively, whereas the removal of phosphorus was observed to be $100 \%$ in the "wetlands" system operating with a hydraulic load of $2.3 \mathrm{~cm} \mathrm{~d}^{-1}$.
\end{abstract}

Key words: constructed "wetlands", post treatment, nutrient removal macrophytes

Recebido em 10/08/1999, Protocolo 088/99

${ }^{1}$ Professor Doutor do Departamento de Química da Universidade Estadual da Paraiba, R. Basílio Araújo 836, Catolé, CEP 58104 - 693, Campina Grande, PB. Fone:(0xx83) 337 1548. E-mail: jtavares@ paqtc.rpp.br

${ }^{2}$ Professor, Ph.D. do Departamento de Engenharia Civil da Universidade Federal da Paraíba, Av. Aprígio Veloso 882, Bodocongó, CEP 58109 - 970, Campina Grande, PB. Telefax: (0xx83) 331 4809. E-mail: prosab@ cgnet.com.br

${ }^{3}$ Graduado em Química Industrial na Universidade Estadual da Paraíba

${ }^{4}$ Mestranda do Programa de Desenvolvimento e Meio Ambiente - PRODEMA UFPB/UEPB, Sub-Área Saneamento Ambiental 


\section{INTRODUÇÃO}

Em regiões de climas tropical e subtropical, a digestão anaeróbia apresenta-se como solução econômica e confiável para o tratamento de esgotos sanitários, mas o processo anaeróbio fornece efluente com constituintes residuais, como gases dissolvidos, matéria orgânica, sólidos suspensos, nutrientes (fósforo e nitrogênio) e organismos patogênicos. Desta forma, efluentes advindos de reator anaeróbio de manta de lodo (reator UASB) necessitam de um pós-tratamento. A disposição de águas residuárias no solo, juntamente com a presença de microrganismos, macrófitas aquáticas e energia solar, resulta na produção de biomassa e energia química, removendo, portanto, carga poluidora e mantendo a conservação dos ecossistemas terrestres e aquáticos. "Wetlands" constituído é um sistema artificialmente projetado para utilizar plantas aquáticas (macrófitas) em substratos (como areia, solo ou cascalho), onde ocorre a proliferação de biofilmes que agregam populações variadas de microrganismos que, através de processos biológicos, químicos e físicos, tratam águas residuárias.

Existem diversos tipos de "wetlands", desde os naturais (charcos, brejos, várzeas e pântanos) até os construídos, que podem ser de fluxo superficial ou subsuperficial (Crites,1994).

Diversas macrófitas aquáticas (emergentes e flutuantes) vêm sendo utilizadas nos sistemas "wetlands" construídos. Segundo Mitchell (1978) apud Thomas et al. (1995) deve-se selecionar as macrófitas obedecendo aos seguintes critérios: (1) fácil propagação e crescimento rápido; (2) alta capacidade de absorção de poluentes; (3) tolerância a ambiente eutrofizado e (4) fácil colheita e manejo.

As macrófitas aquáticas emergentes mais freqüentemente utilizadas são: Typha spp, Phragmites, Juncus ingens e Schoenoplectus validus; por outro lado, tem-se as seguintes macrófitas flutuantes: Eichhornia crassipes (aguapé), Spirodela (erva de pato), Salvinia molesta (salvínia) e Hydrocotyle umbellata.

O presente trabalho teve como objetivo verificar o desempenho de sistema composto por reator anaeróbio de manta de lodo (UASB) seguido de "wetlands" construído, no tratamento de esgotos sanitários, com ênfase na remoção de matéria orgânica carbonácea e nutrientes eutrofizantes (nitrogênio e fósforo).

\section{MATERIAL E MÉTODOS}

O experimento foi instalado e monitorado nas instalações do Programa de Pesquisa em Saneamento Básica (PROSAB), vinculado à Universidade Federal da Paraíba, localizado na cidade de Campina Grande, Paraíba. O sistema foi operado durante o período de vinte e seis semanas (dezembro de 1998 a junho de 1999) divididas em duas fases de 18 e 8 semanas, respectivamente.

O sistema de tratamento constitui-se de duas unidades: a primeira compreende um reator anaeróbio de fluxo ascendente com manta de lodo (UASB), cujas características são apresentadas na Tabela 1. Já para a segunda unidade foram construídos em alvenaria e revestidos internamente com massa impermeabilizante, quatro "wetlands" com área de $10 \mathrm{~m}^{2}$ cada um, conforme Figura 1.
Para melhor distribuição tanto do fluxo de entrada quanto da saída de cada unidade construída, foi depositada uma camada de $30 \mathrm{~cm}$ de largura e $60 \mathrm{~cm}$ de altura de cascalho, com granulometria variando de 15 a $20 \mathrm{~mm}$. O substrato utilizado foi areia grossa lavada com granulometria variando de 2,88 a $4,8 \mathrm{~mm}$, formando uma camada de $60 \mathrm{~cm}$ de altura (Tabela 2), que suportava uma densidade de macrófitas (Juncus sp) de 25 propágulos vegetativos por metro quadrado. Após colocar-se o substrato, transplantaramse 25 propágulos de Juncus sp coletados no açude de Bodocongó; em seguida, adicionou-se água de abastecimento no sistema "wetlands", objetivando-se remover material orgânico eventualmente presente no substrato. $\mathrm{O}$ controle do experimento foi realizado por um sistema "wetlands", contendo apenas substrato não vegetado.

Tabela 1. Características físicas e operacionais do reator UASB

\begin{tabular}{lc}
\hline Características & Magnitude \\
\hline Altura do reator $(\mathrm{m})$ & 3,00 \\
Diâmetro $(\mathrm{m})$ & 0,80 \\
Volume do reator $\left(\mathrm{m}^{3}\right)$ & 1,50 \\
Inóculo & Sem inóculo \\
Tempo de detenção hidráulica (h) & 3,0 \\
Carga orgânica específica kg DQO m & $-3 \mathrm{dia}^{-1}$ \\
\hline
\end{tabular}
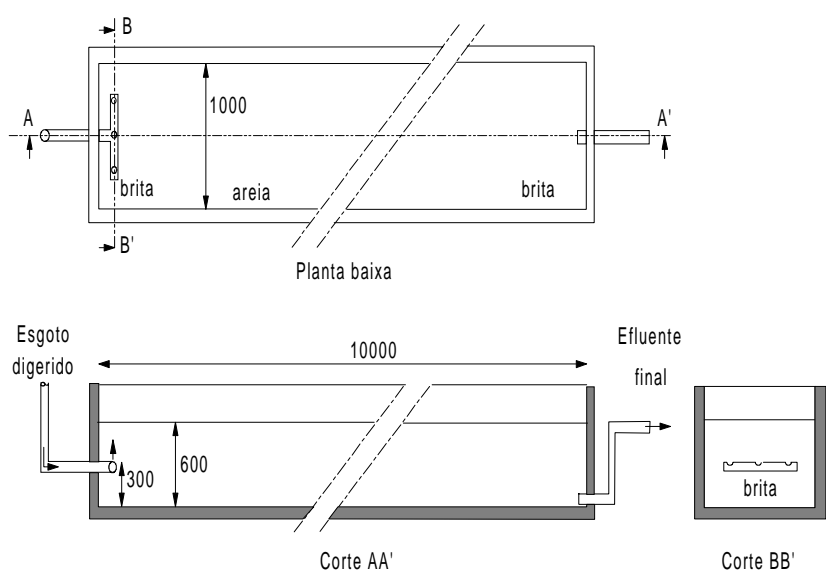

Figura 1. Representação esquemática de uma unidade de "wetlands" (Dimensões em mm)

Tabela 2. Características físicas e operacionais dos sistemas "wetlands"

\begin{tabular}{lc}
\hline Características Físicas & Magnitude \\
\hline Altura do "wetland" construído $(\mathrm{m})$ & 0,80 \\
Altura do substrato $(\mathrm{m})$ & 0,60 \\
Largura $(\mathrm{m})$ & 1,0 \\
Comprimento $(\mathrm{m})$ & 10,0 \\
Área unitária disponível $\left(\mathrm{m}^{2}\right)$ & 10,0 \\
Coeficiente de uniformidade $\left(\mathrm{d}_{60} / \mathrm{d}_{10}\right)$ do substrato & $2,4 \mathrm{e} 3,2$ \\
Granulometria do substrato $(\mathrm{mm})$ & $2,88-4,8$ \\
\hline
\end{tabular}

A alimentação do sistema foi efetuada continuamente. O efluente proveniente do reator UASB era armazenado numa caixa de $100 \mathrm{~L}$ de capacidade, de onde o efluente era bombeado através de bomba peristáltica. As características do efluente do reator UASB, durante todo o período de operação, estão apresentadas na Tabela 3. As vazões eram controladas no início e no final do dia; por outro lado, o afluente do sistema "wetlands" escoa de forma subsuperficial, com vazão diferenciada para cada "wetlands". A carga hidráulica aplicada variou de 2,3 a 4,5 $\mathrm{cm} \mathrm{dia}^{-1}$, 
mas o "wetlands" 3 foi alimentado com a mesma carga do "wetlands" 0 , tido como o controle dos sistemas.

Tabela 3. Características do efluente UASB durante o período de operação

\begin{tabular}{|c|c|c|c|c|c|}
\hline Parâmetros & Fase & $\mathrm{n}^{*}$ & $\begin{array}{l}\text { Valores } \\
\text { Médios }\end{array}$ & $\begin{array}{l}\text { Desvio- } \\
\text { Padrão }\end{array}$ & $\begin{array}{l}\text { Coeficiente de } \\
\text { Variação }(\%)\end{array}$ \\
\hline $\mathrm{pH}$ & $\begin{array}{l}1^{\mathrm{a}} \\
2^{\mathrm{a}}\end{array}$ & $\begin{array}{l}10 \\
10\end{array}$ & $\begin{array}{l}6,8 \\
6,9\end{array}$ & $\begin{array}{l}0,1 \\
0,2\end{array}$ & $\begin{array}{l}1,7 \\
1,7\end{array}$ \\
\hline $\mathrm{DQO}\left(\mathrm{mg} \mathrm{L}^{-1}\right)$ & $\begin{array}{l}1^{\mathrm{a}} \\
2^{\mathrm{a}}\end{array}$ & $\begin{array}{l}20 \\
20\end{array}$ & $\begin{array}{l}289 \\
310\end{array}$ & $\begin{array}{r}103 \\
79\end{array}$ & $\begin{array}{l}36 \\
25\end{array}$ \\
\hline $\begin{array}{l}\text { Nitrogênio Total } \\
\qquad(\mathrm{mg} \text { NTK L L })\end{array}$ & $\begin{array}{l}1^{\mathrm{a}} \\
2^{\mathrm{a}}\end{array}$ & $\begin{array}{l}10 \\
09\end{array}$ & $\begin{array}{l}57,5 \\
59,9\end{array}$ & $\begin{array}{l}12,5 \\
14\end{array}$ & $\begin{array}{l}21 \\
24\end{array}$ \\
\hline $\begin{array}{l}\text { N-amoniacal } \\
\qquad\left(\mathrm{mg} \mathrm{N}^{-} \mathrm{NH}_{4}{ }^{+} \mathrm{L}^{-1}\right)\end{array}$ & $\begin{array}{l}1^{\mathrm{a}} \\
2^{\mathrm{a}}\end{array}$ & $\begin{array}{l}10 \\
09\end{array}$ & $\begin{array}{l}42,5 \\
45,2\end{array}$ & $\begin{array}{l}8,8 \\
6,7\end{array}$ & $\begin{array}{l}20 \\
15\end{array}$ \\
\hline $\begin{array}{l}\text { Fósforo } \\
\qquad\left(\mathrm{mg} \mathrm{P} \mathrm{L}^{-1}\right)\end{array}$ & $\begin{array}{l}1^{\mathrm{a}} \\
2^{\mathrm{a}}\end{array}$ & $\begin{array}{l}12 \\
14\end{array}$ & $\begin{array}{l}5,3 \\
7,2\end{array}$ & $\begin{array}{l}1,6 \\
1,2\end{array}$ & $\begin{array}{l}30 \\
16\end{array}$ \\
\hline $\begin{array}{l}\mathrm{CE} \\
\left.\qquad(\mathrm{dS} \mathrm{m})^{-1}\right)\end{array}$ & $\begin{array}{l}1^{\mathrm{a}} \\
2^{\mathrm{a}}\end{array}$ & $\begin{array}{l}08 \\
05\end{array}$ & $\begin{array}{l}1,7 \\
1,7\end{array}$ & $\begin{array}{l}0,2 \\
0,1\end{array}$ & $\begin{array}{l}12 \\
10\end{array}$ \\
\hline
\end{tabular}

As amostras para determinação de $\mathrm{DQO}$ e $\mathrm{pH}$ foram coletadas com freqüência semanal, porém as formas de nitrogênio, fósforo, sólidos e condutividade elétrica foram determinadas, após as doze semanas do início da operação, com freqüência de duas vezes por semana, durante a primeira e a segunda fases.

Os parâmetros analisados durante o monitoramento foram: temperatura, $\mathrm{pH}$, condutividade elétrica, DQO, $\mathrm{N}_{-} \mathrm{NH}_{4}^{+}{ }_{4} \mathrm{NTK}$ e fósforo total; com exceção das três primeiras determinações, as demais seguiram métodos de análise descritos pelo APHA (1995).

\section{RESULTADOS E DISCUSSÃO}

\section{Condições de operação do sistema}

$\mathrm{O}$ reator UASB foi monitorado com tempo de detenção hidráulica de apenas $3 \mathrm{~h}(0,125 \mathrm{dia})$ e o efluente produzido era dividido para os quatro "wetlands", com vazões diferenciadas; consequientemente, com tempo de detenção hidráulica variando de 5 a 10 dias. A carga aplicada de DQO, de fósforo e das formas de nitrogênio durante o monitoramento dos quatro sistemas "wetlands" está apresentada na Tabela 4.

Os resultados obtidos durante o monitoramento do efluente do reator UASB e dos efluentes dos quatro sistemas "wetlands" estão apresentados nas Tabelas 5 e 6.

Tabela 4. Vazão, tempo de detenção hidráulica e carga aplicada durante o período experimental

\begin{tabular}{|c|c|c|c|c|c|}
\hline \multirow{2}{*}{\multicolumn{2}{|c|}{ Parâmetros }} & \multicolumn{4}{|c|}{ Efluente do "Wetland" } \\
\hline & & 0 & 1 & 2 & 3 \\
\hline \multicolumn{2}{|c|}{$\begin{array}{l}\text { Carga Hidráulica Média } \\
\left(\mathrm{cm} \mathrm{dia}^{-1}\right)\end{array}$} & 2,3 & 4,50 & 3,30 & 2,30 \\
\hline \multicolumn{2}{|l|}{$\begin{array}{l}\text { TDH médio } \\
\text { (dia) }\end{array}$} & 10 & 5,00 & 7,00 & 10,00 \\
\hline $\begin{array}{l}\text { Carga Aplicada } \\
\qquad\left(\mathrm{g} \text { DQO m} \mathrm{mia}^{-1}\right)\end{array}$ & $\begin{array}{l}1^{-\mathrm{a}} \text { fase } \\
2^{\mathrm{a}} \text { fase }\end{array}$ & $\begin{array}{l}6,58 \\
7,06\end{array}$ & $\begin{array}{l}13,17 \\
14,12\end{array}$ & $\begin{array}{r}9,16 \\
10,10\end{array}$ & $\begin{array}{l}6,58 \\
7,06\end{array}$ \\
\hline $\begin{array}{l}\text { Carga Aplicada } \\
\qquad\left(\mathrm{g} \mathrm{NTK} \mathrm{m}^{-2} \mathrm{dia}^{-1}\right)\end{array}$ & $\begin{array}{l}1^{\underline{a}} \text { fase } \\
2^{\underline{a}} \text { fase }\end{array}$ & $\begin{array}{l}1,31 \\
1,33\end{array}$ & $\begin{array}{l}2,62 \\
2,67\end{array}$ & $\begin{array}{l}1,87 \\
1,91\end{array}$ & $\begin{array}{l}1,31 \\
1,33\end{array}$ \\
\hline $\begin{array}{l}\text { Carga Aplicada } \\
\qquad\left(\mathrm{g} \mathrm{P} \mathrm{m}^{-2} \mathrm{dia}^{-1}\right)\end{array}$ & $\begin{array}{l}1^{\underline{a}} \text { fase } \\
2^{\underline{a}} \text { fase }\end{array}$ & $\begin{array}{l}0,12 \\
0,14\end{array}$ & $\begin{array}{l}0,25 \\
0,29\end{array}$ & $\begin{array}{l}0,18 \\
0,21\end{array}$ & $\begin{array}{l}0,12 \\
0,14\end{array}$ \\
\hline
\end{tabular}

Tabela 5. Concentração média dos parâmetros monitorados durante o período experimental

\begin{tabular}{|c|c|c|c|c|c|c|c|c|c|c|c|}
\hline \multirow{3}{*}{ Parâmetros } & \multirow{2}{*}{\multicolumn{3}{|c|}{ Efluente UASB }} & \multicolumn{8}{|c|}{ Efluente do "Wetlands" } \\
\hline & & & & \multicolumn{2}{|c|}{0} & \multicolumn{2}{|c|}{1} & \multicolumn{2}{|c|}{2} & \multicolumn{2}{|c|}{3} \\
\hline & Fase & $1^{\mathrm{a}}$ & $2^{\mathrm{a}}$ & $1^{\mathrm{a}}$ & $2^{\mathrm{a}}$ & $1^{\mathrm{a}}$ & $2^{\mathrm{a}}$ & $1^{\mathrm{a}}$ & $2^{\mathrm{a}}$ & $1^{\mathrm{a}}$ & $2^{\mathrm{a}}$ \\
\hline $\begin{array}{l}\text { DQO } \\
\quad\left(\mathrm{mg} \mathrm{L}^{-1}\right)\end{array}$ & & 282,0 & 310,0 & 78,0 & 80,0 & 54,0 & 65,0 & 45,0 & 59,0 & 46,0 & 50,0 \\
\hline $\begin{array}{r}\text { Nitrogênio Total } \\
\left(\mathrm{mg} \mathrm{NTK} \mathrm{L}^{-1}\right)\end{array}$ & & 57,5 & 59,9 & 42,2 & 40,1 & 23,5 & 21,0 & 23,8 & 20,7 & 13,8 & 7,6 \\
\hline $\begin{array}{l}\mathrm{N} \text {-amoniacal } \\
\quad\left(\mathrm{mg} \mathrm{N}-\mathrm{NH}_{4}{ }^{+} \mathrm{L}^{-1}\right)\end{array}$ & & 42,5 & 45,2 & 35,4 & 35,5 & 20,5 & 18,8 & 20,8 & 18,5 & 11,0 & 6,1 \\
\hline $\begin{array}{l}\text { Fósforo } \\
\qquad\left(\mathrm{mg} \mathrm{P} \mathrm{L}^{-1}\right)\end{array}$ & & 5,3 & 7,2 & 2,5 & 3,6 & 0,6 & 1,55 & 0,6 & 1,15 & 0,0 & 0,0 \\
\hline
\end{tabular}

Tabela 6. Percentagem média de remoção dos parâmetros monitorados durante o período experimental

\begin{tabular}{|c|c|c|c|c|c|c|c|c|c|}
\hline \multirow{3}{*}{ Parâmetros } & & \multicolumn{8}{|c|}{ "Wetlands" } \\
\hline & & \multicolumn{2}{|c|}{0} & \multicolumn{2}{|c|}{1} & \multicolumn{2}{|c|}{2} & \multicolumn{2}{|c|}{3} \\
\hline & Fase & $1^{\mathrm{a}}$ & $2^{\mathrm{a}}$ & $1^{\mathrm{a}}$ & $2^{\mathrm{a}}$ & $1^{\mathrm{a}}$ & $2^{\mathrm{a}}$ & $1^{\mathrm{a}}$ & $2^{\mathrm{a}}$ \\
\hline $\begin{array}{l}\text { DQO } \\
\qquad\left(\mathrm{mg} \mathrm{L}^{-1}\right)\end{array}$ & & 76 & 74 & 81 & 79 & 84 & 81 & 84 & 84 \\
\hline $\begin{array}{l}\text { Nitrogênio Total } \\
\left(\mathrm{mg} \mathrm{NTK} \mathrm{L}^{-1}\right)\end{array}$ & & 27 & 31 & 59 & 65 & 59 & 65 & 76 & 87 \\
\hline $\begin{array}{l}\text { N-amoniacal } \\
\quad\left(\mathrm{mg} \mathrm{N}^{-} \mathrm{NH}_{4}{ }^{+} \mathrm{L}^{-1}\right)\end{array}$ & & 17 & 27 & 52 & 58 & 51 & 59 & 74 & 86 \\
\hline $\begin{array}{l}\text { Fósforo } \\
\qquad\left(\mathrm{mg} \mathrm{P} \mathrm{L}^{-1}\right)\end{array}$ & & 53 & 50 & 88 & 78 & 88 & 84 & 99,9 & 100 \\
\hline
\end{tabular}




\section{Matéria orgânica}

Observando-se a Figura 2, verifica-se que a DQO efluente dos quatro "wetlands" se manteve na média de 78 a $45 \mathrm{mg} \mathrm{L}^{-1}$, durante a primeira fase de operação.

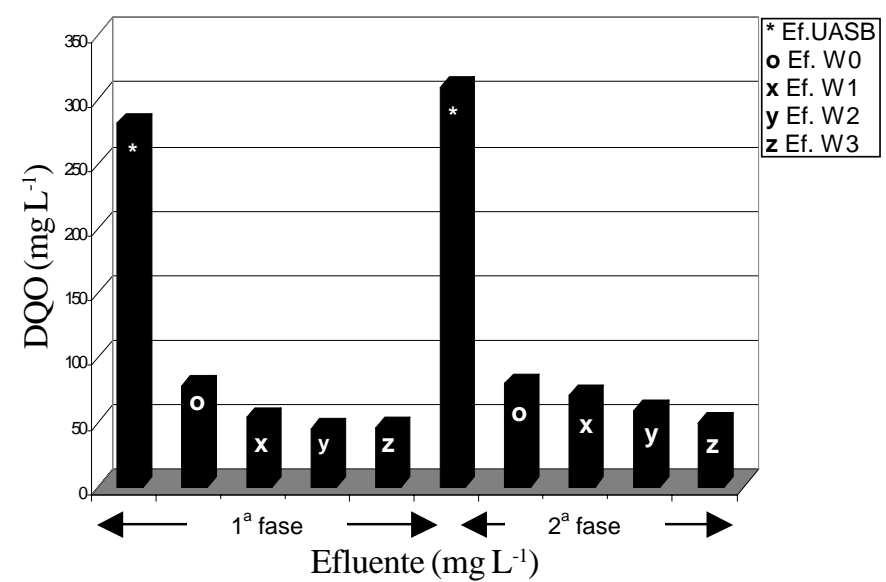

Figura 2. Valores efluentes das concentrações de DQO durante o período de operação dos sistemas "wetlands", à temperatura variando de $19^{\circ}$ a $33^{\circ} \mathrm{C}$

Conforme os dados médios apresentados nas Tabelas 5 e 6 , o aumento da carga hidráulica aplicada não interferiu na qualidade do efluente produzido pelos sistemas. Concluiu-se, então, que os sistemas "wetlands" estavam subcarregados de matéria orgânica e que removeram todo o material biodegradável. Valores de DQO abaixo de $50 \mathrm{mg} \mathrm{L}^{-1}$ nos "wetlands" 2 e 3 (Figura 2) estão na faixa recomendada para descargas em corpos de água (Mendonça, 1990).

As eficiências de cada sistema "wetlands" foram um tanto similar, muito embora o controle ("wetlands" 0) tenha produzido efluente com maior concentração de material orgânico entendendo-se, portanto, que a presença de macrófitas nos sistemas pouco influenciou na remoção de matéria orgânica, enquanto que na segunda fase houve um aumento de $10 \%$ na carga orgânica aplicada e o efluente produzido nos "wetlands" 0 e 1 manteve-se com maior concentração de material orgânico, quando comparado com o da primeira fase (Tabela 5).

A eficiência de remoção, em termos de DQO, durante o período experimental, variou de 79 a $84 \%$ nos três "wetlands" vegetados, (Tabela 6). Sistemas de "wetlands" construídos utilizando cascalhos como substrato, com três diferentes macrófitas, foram estudados por Marques (1999) que obteve remoção, em termos de $\mathrm{DBO}_{5}$, de 74 a $96 \%$, cujos dados confirmam a eficiência na remoção de material orgânico.

\section{Nitrogênio}

As principais transformações com composto de nitrogênio são: assimilação, amonificação, fixação, nitrificação e desnitrificação. Inicialmente, ocorre a amonificação, que é a transformação da matéria orgânica nitrogenada dissolvida ou particulada, mediada por organismos heterótrofos, provavelmente ocorrida no reator UASB (Tabela 5); as demais transformações ocorreram nos sistemas "wetlands".

Neste sentido, as Figuras 3 e 4 apresentam o comportamento das concentrações de nitrogênio total Kjeldhal (NTK) e nitrogênio amoniacal, respectivamente. Observando-se a Figura 3, verifica-se que houve remoção de NTK em todos os sistemas "wetlands", durante a primeira fase de operação, mas a remoção no "wetlands" 0 foi de apenas $27 \%$ na $1^{\text {a }}$ fase e de $31 \%$ na $2^{\text {a }}$ fase, de acordo com a Tabela 6. Entende-se, portanto, que esta remoção se deve apenas ao processo assimilatório das bactérias presentes no biofilme do substrato, na incorporação de $\mathrm{N}-\mathrm{NH}_{4}^{+}$ na estrutura fisiológica celular bacteriana; já na segunda fase de operação, o efluente produzido no "wetlands" 3 manteve-se na média de 6,0 $\mathrm{mg} \mathrm{L}^{-1}$ de nitrogênio na forma de amônia, (Figura 4). Segundo a resolução do Conselho Nacional do Meio Ambiente (CONAMA) nº 20, de 1986, o valor máximo admissível para $\mathrm{N}-\mathrm{NH}_{4}^{+}$é de 5,0 mg N L-1, porém Reis \& Mendonça (1998) asseguram que este valor-limite estabelecido para o efluente é muito rigoroso, sobretudo para $\mathrm{pH}$ do corpo d'água mais ou menos neutro.

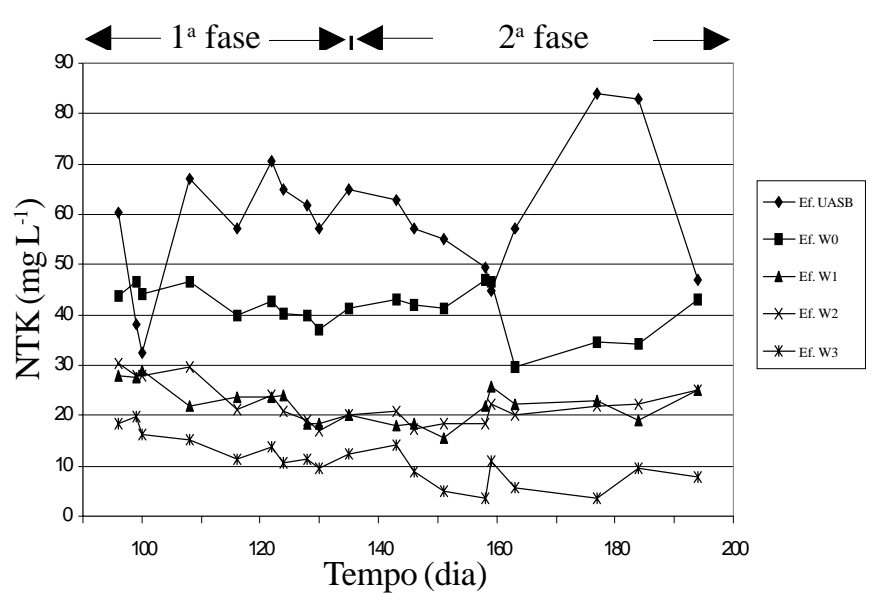

Figura 3. Valores efluentes das concentrações de nitrogênio total durante o período de operação dos sistemas "wetlands", a temperatura variando de $19^{\circ}$ a $33^{\circ} \mathrm{C}$

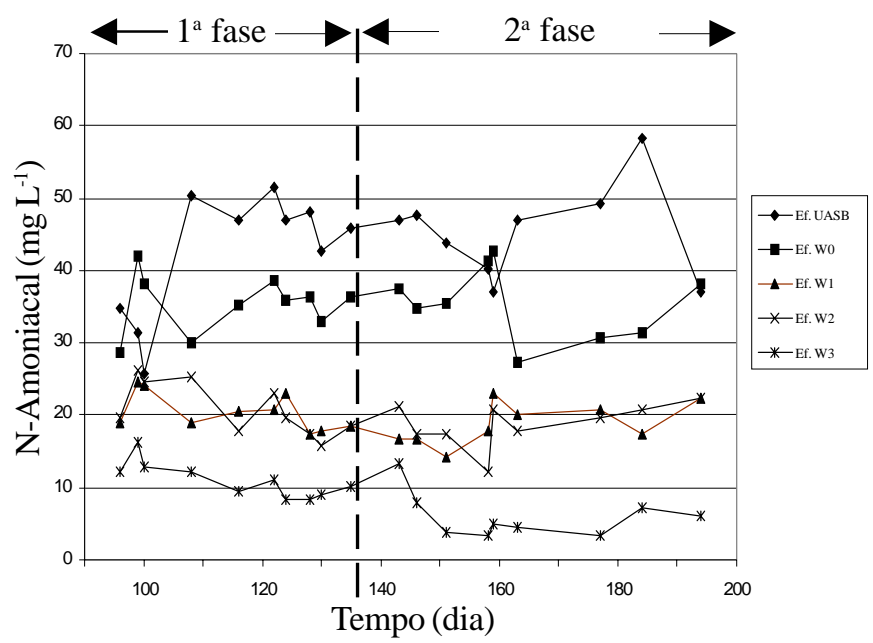

Figura 4. Valores efluentes das concentrações de nitrogênio amoniacal durante o período de operação dos sistemas "wetlands", a temperatura variando de $19^{\circ}$ a $33^{\circ} \mathrm{C}$

Conclui-se, então que, a conversão do nitrogênio amoniacal nos três "wetlands" se deve principalmente a dois fatores básicos: processo assimilatório de microrganismos e macrófitas presentes nos sistemas e nitrificação devido à provável transferência de oxigênio do ar atmosférico pelas folhas das macrófitas aquáticas que, através do aerenquima, permite a distribuição do oxigênio para os rizomas e raízes das plantas (Cooper et al., 1996). 


\section{Fósforo}

O fósforo presente nas águas residuárias, quer seja na forma iônica ou complexada, encontra-se, geralmente, como fosfato e sua remoção por disposição dos esgotos em "wetlands" é controlada pelos processos biótico e abiótico (Reddy \& D’Angelo,1997).

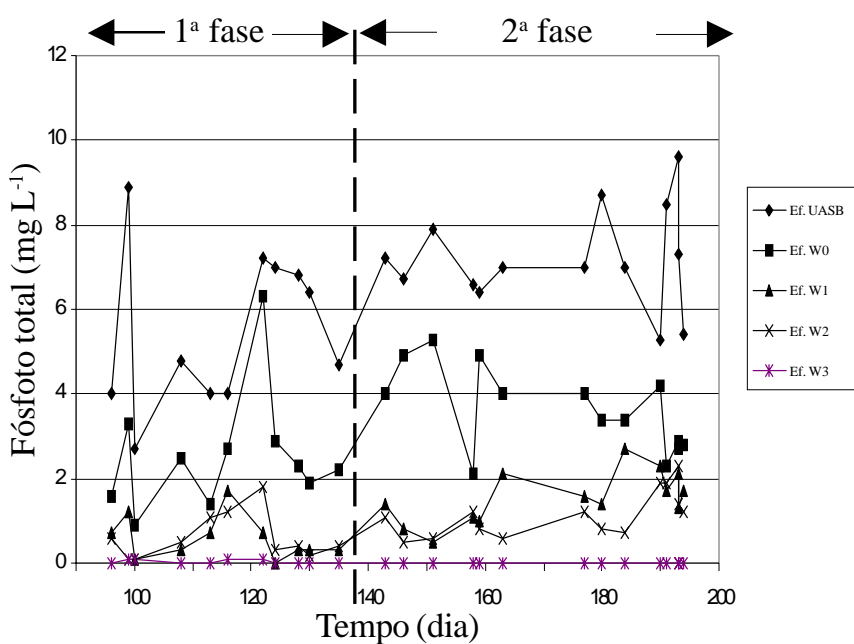

Figura 5. Valores efluentes das concentrações de Fósforo Total durante o período de operação dos sistemas "wetlands", à temperatura variando de $19^{\circ} \mathrm{a} 33^{\circ} \mathrm{C}$

A percentagem média de remoção de fosfato na forma de fósforo total, durante o período de monitoramento dos sistemas "wetlands", está apresentada na Tabela 6, se observa que a remoção no "wetlands" 0 se manteve em torno de 50\%; no entanto, à medida que aumentava o tempo de detenção hidráulica, aumentava também a eficiência de remoção dos sistemas vegetados (Figura 5). O "wetlands" 3 , com carga hidráulica de $2,3 \mathrm{~cm} \mathrm{dia}^{-1}$, teve eficiência total na remoção de fósforo (100\%).

Sousa et al. (1998) ao estudarem um "wetlands" natural com área de $110 \mathrm{~m}^{2}$ e profundidade média de $0,60 \mathrm{~m}$, constituído de macrófitas (Typha sp e Eichhornia crassipes) alimentado com esgotos sanitários $\left(6,6 \mathrm{~cm} \mathrm{dia}^{-1}\right)$, constataram remoção de fósforo total de apenas $66 \%$. Sistema "wetlands" construído, contendo $70 \%$ de areia e $30 \%$ de solo como substratos, foi operado com esgotos sanitários com carga hidráulica de $5 \mathrm{~cm} \mathrm{dia}^{-1}$ e a eficiência de remoção de fósforo total variou de 28 a 41\% (Juwarkar et al.,1995).

Os resultados de remoção de fósforo obtidos (Figura 6), superaram todas as eficiências observadas em sistemas similares (Thomas et al.,1995; Juwarker et al.,1995); assim, entende-se que a total remoção observada se deve à utilização de fósforo por vegetais, perifitos e microrganismos, sedimentação, adsorção, precipitação e processos de troca entre o substrato e a camada de água que se mantém no sistema (Reddy \& D'Angelo,1997).

\section{CONCLUSÕES}

1. Os sistemas "wetlands" funcionaram de forma satisfatória; durante as vinte e seis semanas de operação dos sistemas. A eficiência de remoção de matéria orgânica (DQO) variou de 79 a $84 \%$, enquanto que para nitrogênio total e fósforo essa percentagem foi de 76 a $87 \%$ e de 78 a $100 \%$ portanto, pode-se considerá-los eficientes no pós-tratamento de esgotos sanitários pré-tratados anaerobiamente.
2. A maior eficiência de remoção, tanto de matéria orgânica quanto de nutrientes, ocorreu no "wetlands" que foi monitorado com menor carga hidráulica $\left(2,3 \mathrm{~cm} \mathrm{dia}^{-1}\right)$.

3. Nas condições do experimento, o sistema "wetlands" foi capaz de remover fósforo com eficiência de $100 \%$ e produzir efluente com 6,1 mg N L${ }^{-1}$ de nitrogênio amoniacal $\left(\mathrm{NH}_{3}+\mathrm{NH}_{4}^{+}\right)$; já o ecossistema "wetlands" se comporta como alternativa viável, no pós- tratamento de esgotos sanitários, proveniente de reator UASB.

4. Macrófitas do gênero Juncus sp. apresentaram-se capazes de remover nitrogênio e fósforo de efluente pré-tratado anaerobiamente.

\section{AGRADECIMENTOS}

A investigação experimental foi realizada com apoio do Governo Federal, através da FINEP (PROSAB) e do CNPq e o trabalho foi realizado nas dependências da CAGEPA (Companhia de Águas e Esgotos da Paraíba) em Campina Grande, PB. Os autores agradecem todo o apoio.

\section{REFERÊNCIAS BIBLIOGRÁFICAS}

APHA. AWWA. WPCF. Standard methods for the examination of water and wastewater. 15 ed. Washington, D.C.: American Public Health Association. American Water Works Association, Water Pollution Control Federation, 1995, 1134p.

BRASIL. Leis, Decretos, etc. Resolução CONAMA no 20, de 18 de junho de 1986. In.: Diário Oficial da União. Distrito Federal, jul. 1986.

COOPER, P.F.; GREEN, M.D.; SHUTES, R.B.E. Reed beds and constructed "wetlands" for wastewater treatment. Buckinghamshire: WRC Publications, 1996, 206p.

CRITES, R.W. Designina criteria and practice for constructed wetlands, Water Science Technology, London, v. 29, n. 4, p. 1- 6, 1994.

JUWARKAR, A.S.; OKE, B.; JUWARKAR, A.; PATNAIK, S.M. Domestic wastewater treatment through constructed wetland in India. Water Science Technology, London, v. 32,. 3, p. 291 294, 1995.

MARQUES, D. de M. Terras úmidas construídas de fluxo subsuperficial. In.: CAMPOS, J.R. Tratamento de esgotos sanitários por processo anaeróbio e dispersão controlada no solo. Rio de Janeiro: ABES/PROSAB, 1999.405p., cap. 15, p. 409- 435. MENDONÇA, S.R. Lagoas de estabilização e aeradas mecanicamente: Novos conceitos. João Pessoa, UFPB, 1990.388p.

REDDY, K.R.; D'ANGELO, E.M. Biogeochemical indicators to evaluate polluant removal efficiency in constructed wetlands, Water Science Technology, London, v. 35, n. 5, p. 1 - 10, 1997.

REIS, J.A.T. dos; MENDONÇA, A.S.F. Análise dos padrões para compostos amoniacais segundo a resolução CONAMA 20/86. Engenharia Sanitária e Ambiental, Rio de Janeiro, v. 3, n. 3 e 4, p.146-154,jul./dez. 1998.

SOUSA, J.T. de; OLIVEIRA, J.E.G. de; FLORENTINO, E.R.; GUIMARÃES, A. V.A. Remoção de fósforo através de sistema wetland In.: CONGRESSO INTERAMERICANO DE INGENIERIA SANITARIA Y AMBIENTAL, 26, 1998.CD Rom, Lima: Associación Interamericana de Ingeniaria Sanitária y Ambiental, Lima - Peru: 1998, p. 1 - 8.

THOMAS, P.R.; GLOVER, P.; KALAROOPAN, T. An evaluation of pollutant removal from secondary treated sewage effluent using a constructed "wetland" system. Water Science Technology, London, vol. 32, n. 3, p.87-93, 1995. 